\title{
Effect of temperature on size and shape of silica scales in Synura petersenii and Mallomonas tonsurata (Stramenopiles)
}

\author{
Martina Pichrtová · Yvonne Němcová
}

Received: 4 January 2011 / Revised: 29 April 2011/Accepted: 4 May 2011

(C) Springer Science+Business Media B.V. 2011

\begin{abstract}
Synurophytes are planktonic protists whose cells are covered with silica scales. According to the temperature-size rule, protists decrease in size with increasing temperature. Here, we showed that inorganic silica scales responded to increasing temperature in the same way as the cells did. Two species, Mallomonas tonsurata and Synura petersenii, were cultivated at five temperature levels $(5,10$, 15,20 and $25^{\circ} \mathrm{C}$ ) and the methods of geometric morphometrics were applied for scale size and shape data analyses. We observed that the shape of the scales was significantly affected by the cultivation temperature. The overall shape change from rounded, circular scales to oval or more elongated scales seemed to be a general feature in synurophytes and may be considered a consequence of rising temperature. Moreover, the difference in shape remained significant even if the effect of size (allometric effect) was separated. Finally, we compared the level of the scales' morphological variation among all temperature treatments. The results indicated that the cultivation temperature of $25^{\circ} \mathrm{C}$ negatively affected cellular processes involved in scale biogenesis. The
\end{abstract}

Handling editor: Judit Padisak

M. Pichrtová $(\bowtie) \cdot$ Y. Němcová

Department of Botany, Faculty of Science, Charles

University in Prague, Benátská 2, Praha 2128 01,

Czech Republic

e-mail: pichrtov@natur.cuni.cz use of the scale shape data has potential in palaeoecological research.

Keywords Allometry - Disparity - Geometric morphometrics - Silica scales - Synurophyceae Temperature-size rule

\section{Introduction}

Synurophytes are freshwater flagellate protists. In multigene molecular phylogenetic analyses, synurophytes are included in the Chrysophyceae/Synurophyceae clade (e.g., Grant et al., 2009) within the Stramenopiles. Most species of the class belong to the individually living genus Mallomonas, and the colonial genus Synura whose cells are connected by their narrow posterior stalks. Synurophytes are characterised by silica scales (ca. $4 \mu \mathrm{m}$ long) that cover their cells and form an imbricated layer on the surface. In Mallomonas, some or all scales may harbour a bristle and the mean number of scales per cell differs among individual Mallomonas species (Siver, 1991). Scales are produced intracellularly within silicon deposition vesicles; a chloroplast endoplasmic reticulum serves as a shape-matrix. Two main types of scales can be discerned within the scale cover of Synura petersenii Korshikov cells: oblong body scales with a dorsal ridge and narrow rear scales with a reduced structure (Kristiansen \& Preisig, 2007). Mallomonas tonsurata Teiling em. Krieger has four types of scales: domed apical, domed body, domeless body and 
domeless rear scales. The domed body scales used in this study are located only on the anterior part of the cells (Siver, 1991). The term 'dome' refers to the part of a scale where bristle is attached (Fig. 1). The scale morphology has been instrumental in the determination and taxonomy of synurophytes since the mid sixties, when the transmission electron microscope became widely used. As silica structures remain preserved in lake sediments, synurophytes represent valuable bioindicators of either present or past environmental conditions (e.g., Rojackers \& Kessels, 1986; Smol, 1995). However, even among scales belonging to one species, there is relatively great morphological variation (Kristiansen, 1979). Probably the most important factor affecting this variation is the position on the cell (Siver, 1991; Neustupa et al., 2010). Nevertheless, it has been demonstrated that environmental conditions influence the overall shape variations of synurophyte scales (Neustupa \& Němcová, 2007; Němcová et al., 2010; Řezáčová-Škaloudová et al., 2010).

One of the most important ecological factors affecting the biology of planktonic organisms is water temperature. The shift of species composition of synurophytes along a temperature gradient is well documented; temperature controls seasonal occurrence and species abundance (Rojackers \& Kessels, 1986; Siver, 1995). Atkinson (1994) proposed a general rule describing the relationship between temperature and size of ectotherm organisms, which was further expanded to protists (Atkinson et al., 2003). Two explanations were proposed: (1) the cells compensate for an increased demand for resources in a warmer environment by reducing their size and hence increasing their surface to volume ratio and (2) selection pressure for earlier completion of cell cycle is higher since the offspring of smaller maternal cells, dividing earlier, will form a larger fraction of the population. According to this rule, organisms decrease in size with increasing temperature (within the temperature range normally encountered in their natural environment). Outside this range, the response may differ. At low sublethal temperatures, a reduction in size occurred while at high sub-lethal temperatures, both a reduction as well as a further increase in cell size was observed (Atkinson et al., 2003). However, the question remains whether scales are affected by temperature in the same way as the cells are. Unlike cells, the silica scales are inorganic structures that do not grow or change their shape once they are deposited onto the cell surface (Wetherbee et al., 1995). The expansion of cell size prior to cell division is a natural process. During interphase, the number of scales doubles but their sizes remain unchanged (Lavau \& Wetherbee, 1994). The silica structures were hypothesised to reflect the cell expansion caused by decreasing temperatures (MartinWagenmann \& Gutowski, 1995; Gutowski, 1996).
Fig. 1 Morphological structures and the position of individual landmarks (squares) and semilandmarks (circles) on silica scales. a Synura petersenii and b Mallomonas tonsurata. $K$ keel, $R$ rim, $D$ dome, $V$ V-rib. Bar $1 \mu \mathrm{m}$
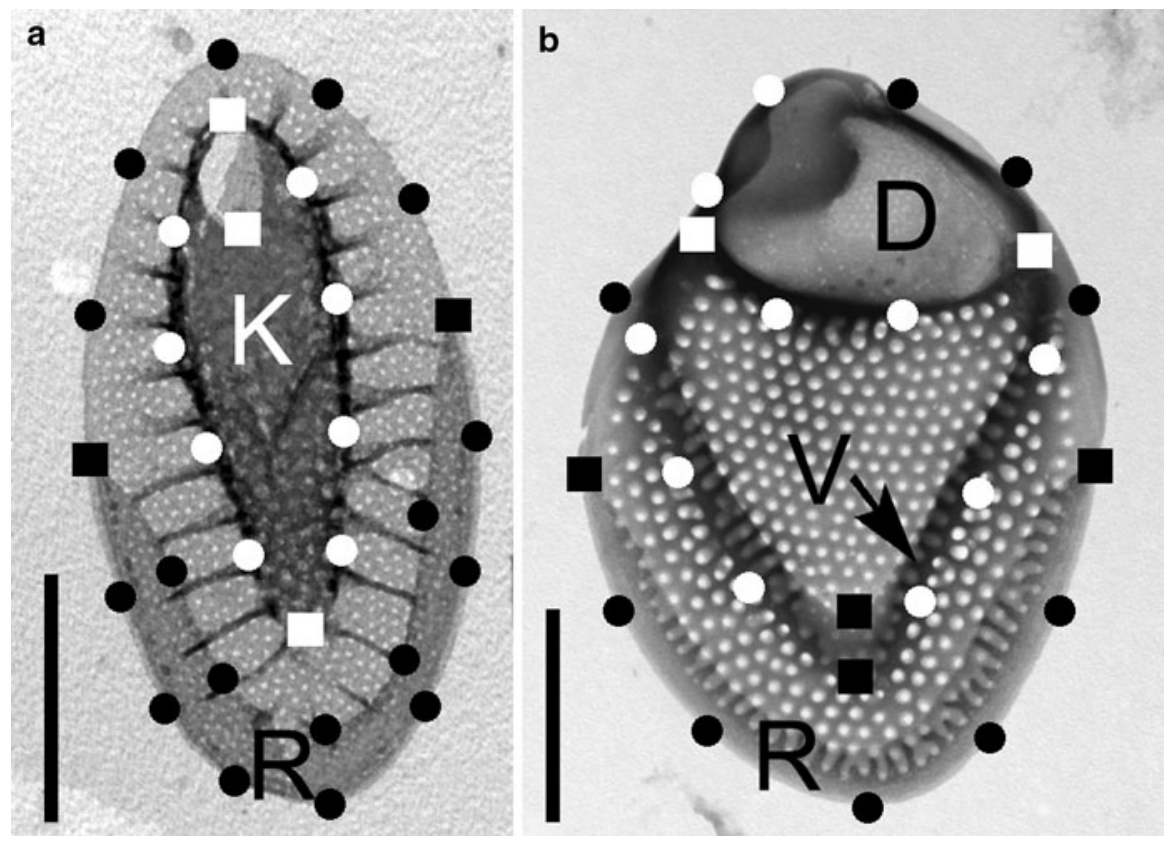
However, an experimental approach combining the investigation of scale size and cell size is still missing.

Several studies have already been performed trying to reveal how exactly water temperature affects the morphology of newly synthesised silica scales using traditional distance-measuring methods (Martin-Wagenmann \& Gutowski, 1995; Gutowski, 1996; Siver \& Skogstad, 1988). More recently, several studies have targeted the impact of temperature on scale shape, using a modern methodological approach of geometric morphometrics (GM) (Němcová et al., 2010; Řezáčová-Škaloudová et al., 2010). Geometric morphometrics is currently a popular tool in evaluating shape as a whole and has already been used in many fields of biology. It is based on the analyses of configurations of homologous points (landmarks) (Bookstein, 1991; Zelditch et al., 2004).

Here, we supply detailed information on the effects of temperature on scale shape and size of two synurophyte species: Mallomonas tonsurata and Synura petersenii. Both species are reported to occur in a wide range of temperature in nature. For example, $S$. petersenii was found in plankton samples at temperature of $4.7^{\circ} \mathrm{C}$ (Němcová, 2010) and at temperature higher than $25^{\circ} \mathrm{C}$ (Padisák et al., 2000). Similarly, $M$. tonsurata occurred in plankton at temperature of $0^{\circ} \mathrm{C}$ (Janatková \& Němcová, 2009) and at temperature up to $30^{\circ} \mathrm{C}$ (Neustupa \& Řezáčová, 2007).

Moreover, we have extended previous research by investigating both allometric and non-allometric patterns in scale shape plasticity. Usually, a large fraction of the variation in shape data is due to size variation among investigated objects. Allometric relationships uncover size-related variations in shape. Both size and shape represent important properties of organisms, with important functional and ecological implications (Marroig, 2007). The geometric morphometrics approach allowed the precise separation of shape variation associated with size (allometric) and shape variation unassociated with size (nonallometric). Finally, we also investigated the extent of morphological variation within the scales produced under various cultivation temperatures.

\section{Materials and methods}

The Synura petersenii strain was isolated from a forest pool in National Park Bohemian Switzerland
(5052’37.994”N, 14¹9'10.614”E) in February 2007 and the Mallomonas tonsurata strain from a pond in Prague (50¹'46.664”'N, 14³2'59.814”E) in November 2007. Batch cultures were kept in DY IV medium (Andersen et al., 1997) at $15^{\circ} \mathrm{C}$ under continuous light $\left(30 \mu \mathrm{mol} \mathrm{m} \mathrm{m}^{-2} \mathrm{~s}^{-1}\right)$. The experiments were carried out simultaneously in serological plates: 20 wells were used for each experimental temperature. For each strain, five plates were placed in thermostat boxes with set temperatures of 5, 10, 15, 20 and $25^{\circ} \mathrm{C}$. The illumination inside the boxes was $35 \mu \mathrm{mol} \mathrm{m} \mathrm{s}^{-1}$ with $16: 8 \mathrm{~h}$ light:dark cycle. Initially, each well in the five plates filled with fresh DY IV medium was inoculated with 2-3 Synura colonies or approximately 10 Mallomonas cells. The cultivation lasted 20-30 days, until the populations were dense enough to provide a large number of scales produced under the tested experimental conditions (ca. 40,000 cells $\mathrm{ml}^{-1}$; corresponding to the visible turbidity). Cells from a culture plate (20 wells) were combined and treated as a single sample, contaminated wells or those where populations did not grow were excluded. For electron microscopy, the samples were dried on Formvar-coated copper grids. The grids were then examined under a TEM JEOL 1011 transmission electron microscope. For each temperature treatment, 50 body scales and 50 domed body scales were randomly chosen and photographed in Synura petersenii and Mallomonas tonsurata, respectively. Weakly silicified or broken scales were excluded from the shape analysis due to the lack of homologous structures.

The shape of the silica scales was investigated using landmark-based methods of geometric morphometrics. This approach uses a defined group of homologous points (landmarks). We defined 30 and 25 landmarks on Synura petersenii and Mallomonas tonsurata scales, respectively. Semilandmarks were allowed to slide along the outline of the scale (Bookstein, 1997). For positions of individual homologous points and scale terminology, see Fig. 1. The geometric morphometric data was analysed by TPS series software (Rohlf, 2006), the statistical analyses were performed in PAST (Hammer et al., 2001). The landmark configurations were superimposed by generalised Procrustes analysis (Zelditch et al., 2004). Then, the PCA (principal component analysis) of Procrustes aligned data was carried out for the whole datasets of 250 scales. We used the scores on the first 
8 (for $S$. petersenii) and 9 (for $M$. tonsurata) principal components (PCs) for further statistical analyses: MANOVA (multivariate analysis of variance) and CVA (canonical variates analysis). These PC axes described altogether 91.1 and $91.4 \%$ of the total shape variation in $S$. petersenii and $M$. tonsurata, respectively, and were found to be significant by the Joliffe cut-off value (Jolliffe, 1986). The pairwise comparisons of individual temperature groups were performed as two-group multivariate permutation tests (2,000 permutations) on Mahalanobis distance. Shape configurations typical for individual treatments were visualised as thin-plate splines deformation grids depicting the morphological trends between average group shapes and the overall consensus configurations. Multivariate regression of shape data with temperature as the independent variable was then performed. To determine the effect of temperature on shape, with size-effect controlled, the allometric shape variation was separated (Debat et al., 2003; Černá \& Neustupa, 2010). First, we performed a multivariate regression of shape data on the centroid size (CS) of the scales. CS is defined as the square root of the sum of squared distances from the landmarks to their centroid (Zelditch et al., 2004). Then, we used residuals from this regression (in $\mathrm{R}$, version 2.6.2) for PCA analysis. Scores on the first 9 (11) PC axes spanning $92.0 \%(93.5 \%)$ of the total variation for $S$. petersenii (M. tonsurata) were used for MANOVA, CVA and two-group permutation tests. Also, multivariate regression of non-allometric (size-independent) shape data on temperature was conducted and significance of the tests was tested by permutation tests (1,000 permutations). The residuals were added to consensus configurations in order to visualise non-allometric shape as deformation grids.

Centroid size and scale length were used as scale size variables. To test the difference in size between individual treatments, permutation $t$ tests were used (10,000 permutations). Moreover, correlation between the size and temperature was counted. We also examined the relationship between Synura petersenii cell volume and cultivation temperature. Fifty cells from each temperature treatment were randomly chosen, their width and length were measured and approximate volume was counted according to Hillebrand et al. (1999). To quantify the extent of morphological variation within individual temperature groups, we took the scores of the objects (individual landmark configurations) in the PCA ordination space and counted the Euclidean distance between all pairs of objects (within one group). The differences in mean Euclidean distances between individual treatments were tested by permutation tests (10,000 permutations).

\section{Results}

Both centroid size and length of scales at the individual temperature levels are shown in Fig. 2a-d. In both species, there was a significant decrease in the centroid size with increasing temperature ( $\mathrm{rs}=-0.44$, $P$ permutation $<0.001$ for Synura petersenii and rs $=-0.64, P$ permutation $<0.001$ for Mallomonas tonsurata). Similarly, the length of scales decreased ( $\mathrm{rs}=-0.45, P$ permutation $<0.001$ for $S$. petersenii and $\mathrm{rs}=-0.62, P$ permutation $<0.001$ for $M$. tonsurata. However, $S$. petersenii scales increased in size when cultivated under $25^{\circ} \mathrm{C}$. Therefore, the negative correlation was stronger after the elimination of the $25^{\circ} \mathrm{C}$ treatment (centroid size: $\mathrm{rs}=-0.55, P<0.001$; scale length: $r s=-0.54, P<0.001)$. A similar response was revealed in the size (expressed as cell volume) of $S$. petersenii cells ( $\mathrm{rs}=-0.2, P<0.001$ for all temperature treatments; $\mathrm{rs}=-0.59, P<0.001$ when $25^{\circ} \mathrm{C}$ temperature treatment was omitted), see Fig. 3. Furthermore, the relative thermal sensitivity of cell volume was counted according to Atkinson et al. (2003). We revealed for each $1^{\circ} \mathrm{C}$ increase, a cell volume reduction of $2.96 \%$ of the volume observed at $15^{\circ} \mathrm{C}$ in $S$. petersenii, within the temperature range $5-20^{\circ} \mathrm{C}$.

The PCA analyses of the shape data were performed on the whole set of 250 scales. The MANOVA analysis was significant for both species investigated $(S$. petersenii: Wilks' $\lambda$ : $0.2745 ; F=11.54 ; P<0.001$; M. tonsurata: Wilks' $\lambda=0.2517 ; F=11 ; P<0.001$ ) and the CVA clearly discriminated between all the temperature groups. The permutation tests on the values of Mahalanobis distances showed significant differences between all pairs of groups in both species. Also, in both cases, the scales from the lowest $\left(5^{\circ} \mathrm{C}\right)$ and highest $\left(25^{\circ} \mathrm{C}\right)$ temperature levels were well segregated along the first canonical axis that leads in the direction of highest among-group variation (Fig. 4a, b). Moreover, temperature explained a significant proportion of the overall shape variation in multivariate regression (4.87\% in S. petersenii and $7.06 \%$ in M. tonsurata). 

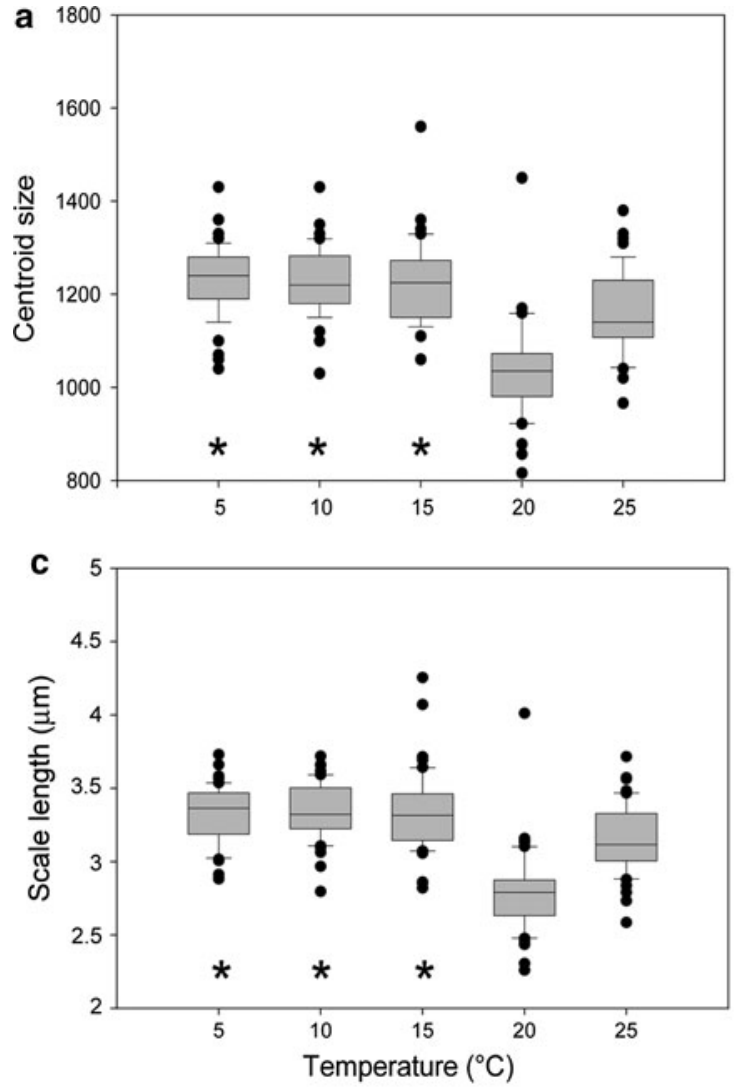

Fig. 2 Size of silica scales expressed as centroid size and length of scales in different temperature treatments. a Synura petersenii-centroid size, b Mallomonas tonsurata-centroid

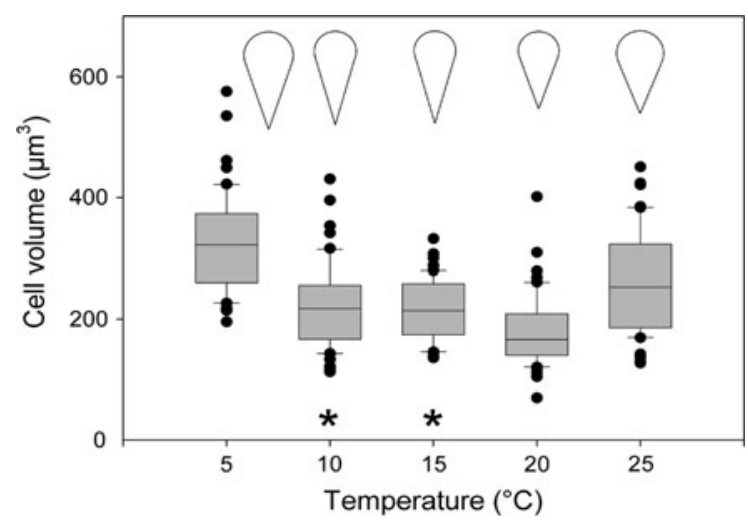

Fig. 3 Cell volume of Synura petersenii cells in different temperature treatments and mean cell shape reconstructions. Groups marked with an asterisk are not significantly different in their mean cell volume

In both the investigated species, the shape of the scales was significantly related to cultivation temperature.
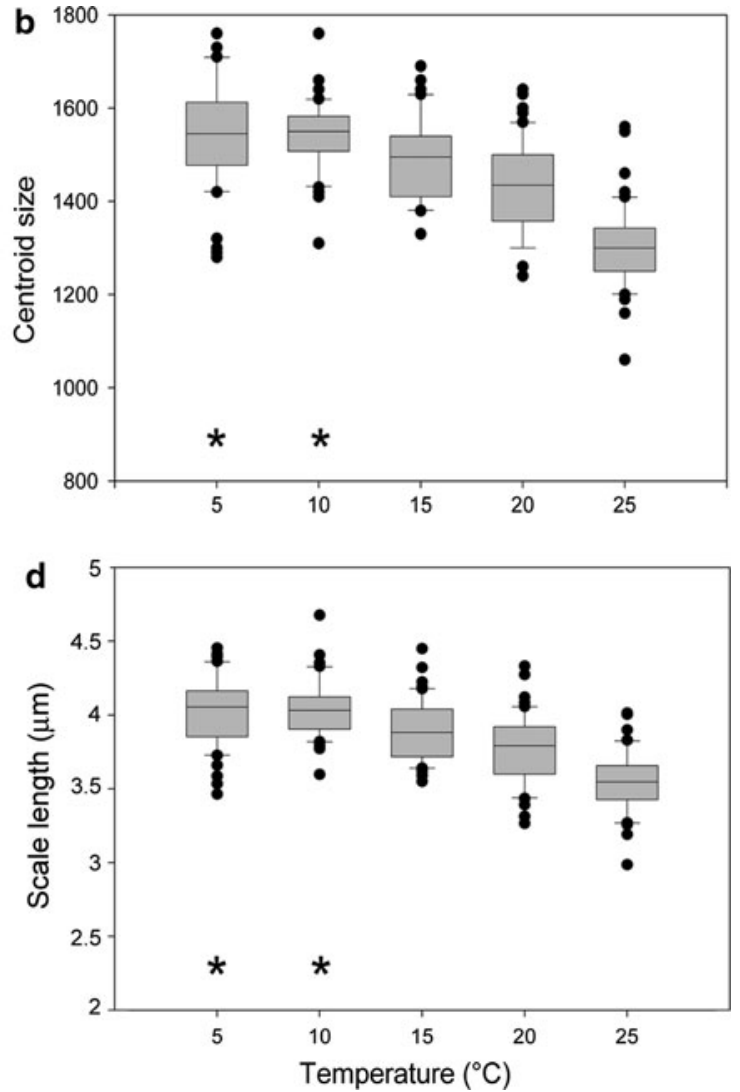

size, c S. petersenii-scale length, d $M$. tonsurata-scale length. Groups marked with an asterisk are not significantly different in their mean centroid size (scale length)

The morphological trends typical for each temperature level were depicted as deformation grids (Fig. 5a, b). In S. petersenii, the dorsal ridge (keel) was markedly narrower at higher temperatures. Conversely, the rim was wider. Furthermore, the scales from $25^{\circ} \mathrm{C}$ had their distal part apparently shorter in comparison to other groups. The most distinct morphological feature in $M$. tonsurata scales was the varying proportion of the dome within the area of the whole scale. At higher temperatures, the dome became relatively larger. Besides this, the shape of the V-rib differed among individual temperature levels.

A significant allometric effect of size on the shape was revealed. Multivariate regression models of shape data on the centroid size explained $5.4 \%$ of total shape variance (Wilk's $\lambda=0.3$, permutation $P=0.001$, Goodall's $F=14.575$, permutation $P=$ 0.001 ) in S. petersenii and $12.2 \%$ (Wilk's $\lambda=0.14$, 

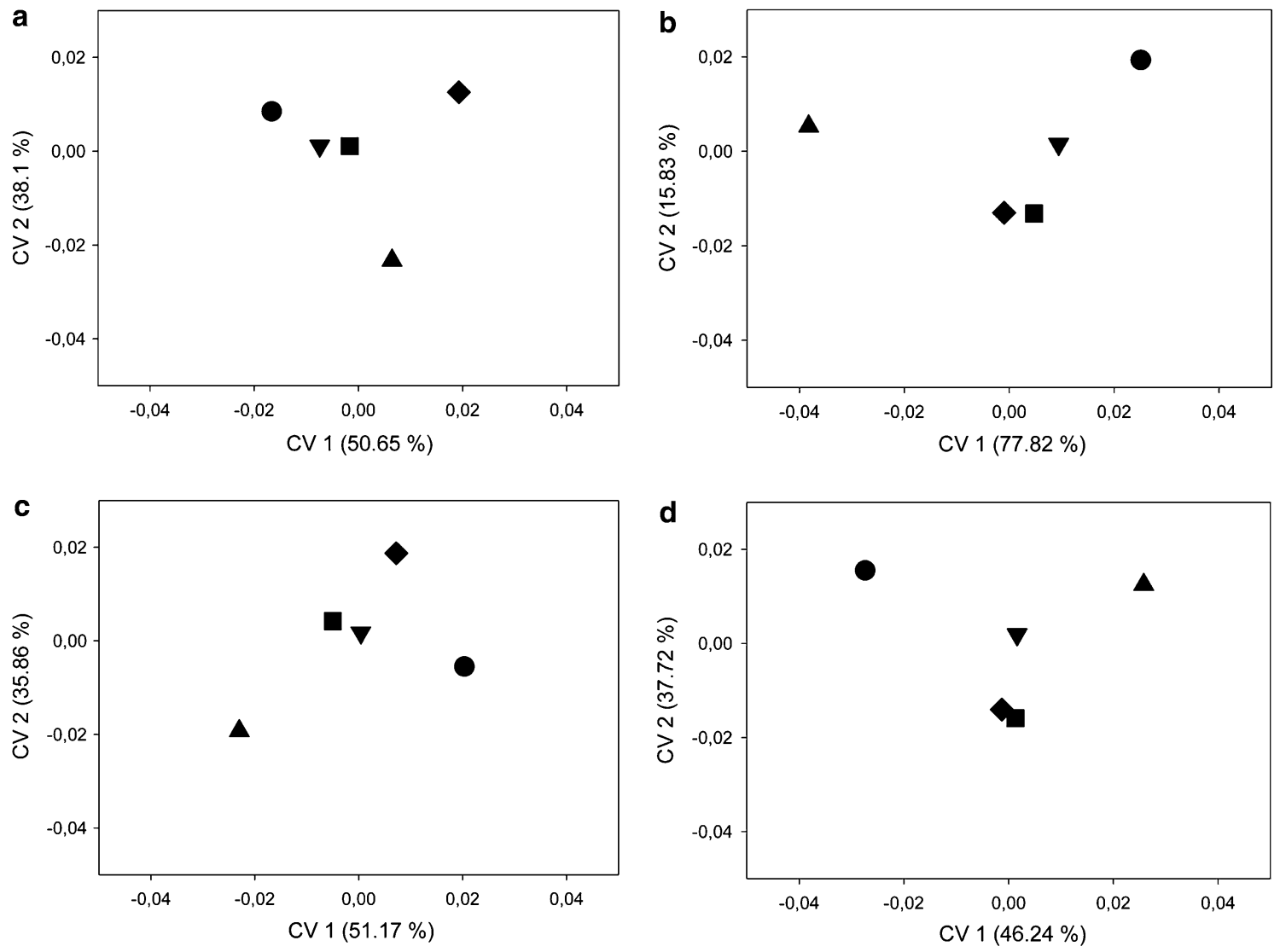

Fig. 4 CVA ordination plots showing mean (centroid) position of each temperature group. a Synura petersenii, overall shape variation, b Mallomonas tonsurata, overall shape variation, c $S$. petersenii, non-allometric shape variation and

d $M$. tonsurata, non-allometric shape variation. Filled circle $5^{\circ} \mathrm{C}$, inverse triangle $10^{\circ} \mathrm{C}$, filled square $15^{\circ} \mathrm{C}$, filled diamond $20^{\circ} \mathrm{C}$ and filled triangle $25^{\circ} \mathrm{C}$

permutation $P=0.001$; Goodall's $F=33.997$, permutation $P=0.001)$ in $M$. tonsurata. A comparison of the proportion of the explained variation showed that the overall shape was actually more affected by size than by cultivation temperature. Therefore, we removed the effect of allometric shape variation and focused on the effect of temperature itself. The PCA was carried out on the residuals from the multivariate regression of shape data on the centroid size. MANOVA was significant for both species $(S$. petersenii: Wilks' $\lambda=0.4194, F=6.451, P<0.001 ; M$. tonsurata: Wilks' $\lambda=0.4838, F=4.279 ; P<0.001)$. The CVA ordination plots illustrating the non-allometric shape variation are shown in Fig. $4 \mathrm{c}$ and $\mathrm{d}$ and corresponding deformation grids in Fig. 5c and d. All pair wise comparisons on Mahalanobis distances proved that the different temperature groups were still significantly different in their shape (permutation

$P<0.01)$. In S. petersenii, the discrimination between the two extreme temperature treatments was even better compared to the overall shape analysis (compare Fig. $4 \mathrm{a}, \mathrm{c}$ ). The multivariate regression of the nonallometric (size-unrelated) component of shape on temperature was still significant and explained 2.9 and $5.1 \%$ of the total variation in $S$. petersenii and $M$. tonsurata, respectively. As this proportion is lower than in the overall shape analysis, it is apparent that the discrimination between the temperature groups was at first indeed affected by the different size of the scales. Slight differences in shape were also observed on the shape reconstructions but in general, the pattern of shape dynamics remained very similar (Fig. 5). In both the investigated species, the scales from the $25^{\circ} \mathrm{C}$ treatment remained the most different in their overall shape. Markedly, the shape of the $S$. petersenii scales from the $20^{\circ} \mathrm{C}$ treatment did not differ so clearly from 

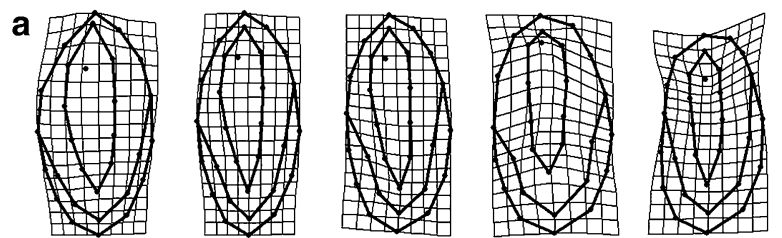

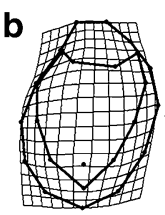

$5^{\circ} \mathrm{C}$

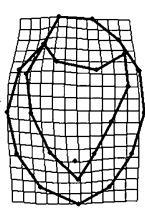

$10^{\circ} \mathrm{C}$

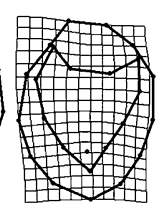

$15^{\circ} \mathrm{C}$

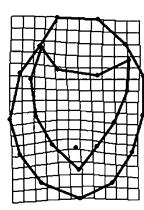

$20^{\circ} \mathrm{C}$
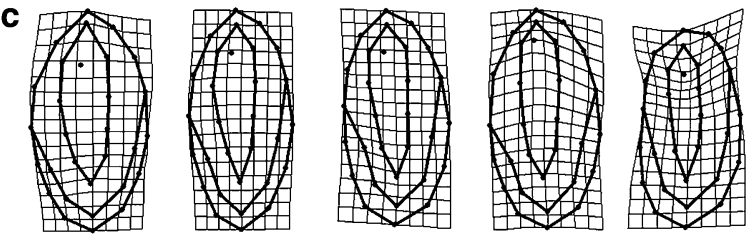

d

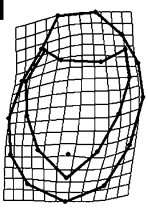

$5^{\circ} \mathrm{C}$

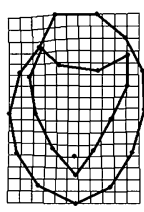

$10^{\circ} \mathrm{C}$

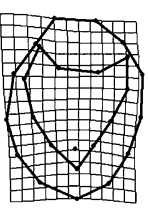

$15^{\circ} \mathrm{C}$

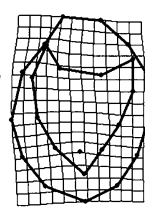

$20^{\circ} \mathrm{C}$

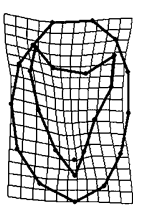

$25^{\circ} \mathrm{C}$
Fig. 5 Thin plate splines showing morphological trends characteristic for the mean scale shape for each treatment. a Synura petersenii, overall shape variation, b Mallomonas tonsurata, overall shape variation, c $S$. petersenii, non-

the others as that before the removal of the allometric variation. Moreover, the dome area in M. tonsurata did not vary further among the treatments, showing that these morphological trends were in fact a consequence of different scale size in individual temperature groups.

The extent of morphological variation at different temperature levels is depicted in Fig. 6. In S. petersenii, the lowest shape variation was within the $15^{\circ} \mathrm{C}$ group (but was not significantly different from that at 5 and $20^{\circ} \mathrm{C}$ ). On the other hand, the scales were morphologically most diverse at the highest investigated temperature $\left(25^{\circ} \mathrm{C}\right)$. The $M$. tonsurata scales were the least variable in morphology at $15^{\circ} \mathrm{C}$. Both the decreasing and increasing cultivation temperatures

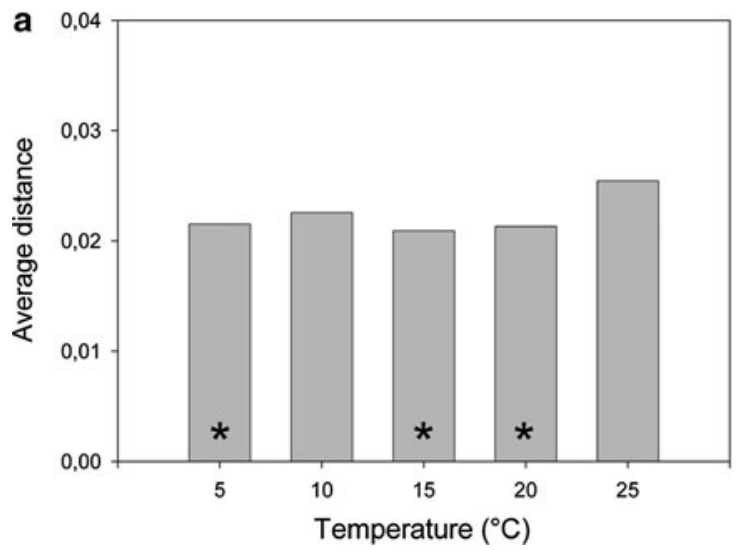

Fig. 6 The extent of morphological variation in particular temperature treatments expressed as the average Euclidean distance among the specimens in the PCA ordination space. allometric shape variation and $\mathbf{d} M$. tonsurata, non-allometric shape variation. Scale factor: three times magnified to emphasise differences

caused a significant increase in morphological variation.

\section{Discussion}

The temperature-size rule, expressed as a negative regression of size or volume over temperature, was present in the scales of both the investigated species and in the cells of $S$. petersenii as well. The cells of $S$. petersenii decreased in size (here expressed as volume) consistently from 5 to $20^{\circ} \mathrm{C}$ congruently with the temperature-size rule (Atkinson, 1994; Atkinson et al., 2003), while their volume increased again at a higher cultivation temperature $\left(25^{\circ} \mathrm{C}\right)$.

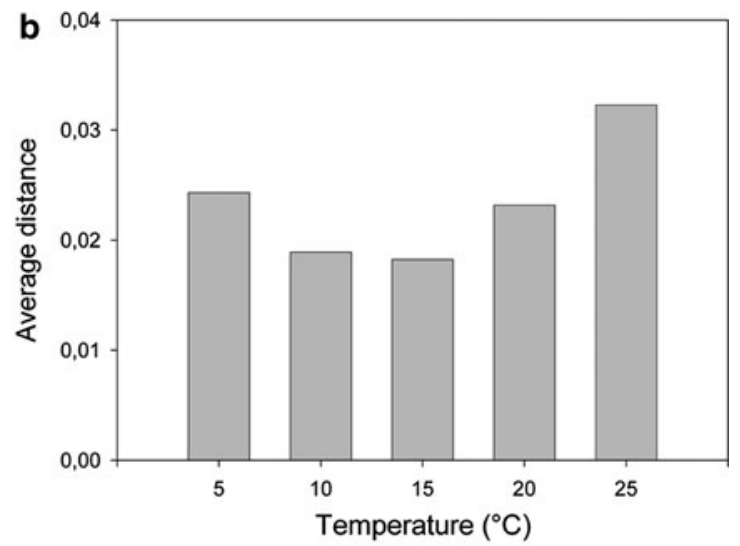

a Synura petersenii and b Mallomonas tonsurata. Groups marked with an asterisk are not significantly different in their average Euclidean distance 
Such a response was demonstrated for the temperature above the range where temperature-related sizereduction rule applies (outside the range of normally encountered conditions) e.g., for the diatom Coscinodiscus at $24^{\circ} \mathrm{C}$ (Montagnes \& Franklin, 2001). This is not surprising since in natural localities of temperate regions, planktonic organisms rarely encounter a constant water temperature of $25^{\circ} \mathrm{C}$ or higher for long periods of time. Size-reduction trend was observed in inorganic silica scales of both the investigated species (the scales decreased in size through the whole range of experimental conditions in $M$. tonsurata). Consequently, we consider that an increasing cultivation temperature leads to the production of smaller cells with smaller scales and vice versa. We are aware of the fact that more species have to be experimentally examined to verify this assumption. A scale size reduction with increasing temperature has already been demonstrated in M. tonsurata (Gutowski, 1996). However, only one of three investigated strains of $S$. petersenii decreased the scale size significantly with increasing temperature in the study by Martin-Wagenmann \& Gutowski (1995). In other synurophyte species, Mallomonas kalinae Řezáčová and Synura curtispina (Petersen \& Hansen) Asmund, scales decreased in size with increasing temperature but increased again in size at the highest experimental level $\left(30^{\circ} \mathrm{C}\right)$ (ŘezáčováŠkaloudová et al., 2010). Moreover, the temperaturerelated shape change of single cells may have subsequent effects on the number of cells in a colony (Fig. 3). Rounded cells with short stalks have lower potential to build up the colonies with high number of cells simply for mechanistic reasons. However, we did not count cells comprising $S$. petersenii colonies as it was beyond the scope of this work.

The cultivation temperature had a significant impact on the shape of silica scales in both the investigated species, although only a small amount of the overall variation was explained by particular regression models. The average scale shape differed significantly amongst all temperature groups in both M. tonsurata and S. petersenii (Fig. 5a, b). It was difficult to compare the morphological trends in both the investigated species because the scale structures were not homologous and different sets of landmarks were used. Nevertheless, the overall shape change from rounded, circular scales to oval or more elongated scales was traced in both $M$. tonsurata and S. petersenii. Similar morphological trends associated with temperature have also been observed in different S. petersenii strains (Martin-Wagenmann \& Gutowski, 1995) and S. curtispina (̌̌ezáčováŠkaloudová et al., 2010). The above-described shape change seems to be a general feature in synurophytes and may be considered a consequence of rising temperatures. In $S$. petersenii, we revealed that the scales with a large prominent keel were accompanied by a reduced thin rim at low temperatures. On the other side of the temperature gradient, the scales had a highly reduced thin keel and a wide expanded rim. Our findings are consistent with previous results from Němcová et al. (2010), who suggested a compensatory principle accompanying the scale shape change. The scales change their shape within a certain 'frame' where one change in scale morphology is compensated by the other one in order to retain scale firmness. The effect of temperature on $M$. tonsurata scales has already been studied by the means of traditional morphometrics (Gutowski, 1996). Employing more detailed methods of GM, we confirmed some of the shape trends, such as the shortening of scales, expanding of the dome area and the V-rib shape varying between a ' $U$ '-like and ' $V$ '-like form. On the other hand, the scales produced at $5{ }^{\circ} \mathrm{C}$ in our temperature experiment differed considerably in shape from those published previously. However, Gutowski (1996) noted that her investigated population of $M$. tonsurata did not grow well at $5^{\circ} \mathrm{C}$. Consequently, the scales used in the analysis might have belonged to the inoculum cells and might not have been produced under the experimental conditions at $5^{\circ} \mathrm{C}$.

Allometry is a common phenomenon in living organisms. Usually, a large portion of shape variation is connected with a size change accompanying growth. For example, size accounted for $23.8 \%$ of the total shape variation in the Drosophila wing (Debat et al., 2003), 37.5\% in a desmid Micrasterias rotata Ralfs (Neustupa et al., 2008) and $13.9 \%$ in coenobial green alga Pediastrum duplex Meyen (Neustupa \& Hodač, 2005). This was also observed in the present study where the size significantly affected scale shape. Scales represent firm inorganic structures, which do not change their shape once they are exocytosed to the cell surface (Leadbeater \& Barker, 1995; Wetherbee et al., 1995). The sizerelated shape change in silica scales is not connected with growth but rather with the position of the scale 
on the cell surface (Neustupa et al., 2010; ŘezáčováŠkaloudová et al., 2010). Consequently, the allometric effect is weaker, accounting for 5.3 and $12.2 \%$ in $S$. petersenii and $M$. tonsurata, respectively. The separation of the allometric effect enables us to study the size-independent effect of cultivation temperature on scale shape. Distribution of group centroids on CVA ordination plots differed only slightly between both types of analyses (allometric vs. non-allometric shape data, Fig. 4). Analysis of size-dependent (allometric) variation revealed scales produced at $20^{\circ} \mathrm{C}$ in $S$. petersenii and at $25^{\circ} \mathrm{C}$ in $M$. tonsurata to be the most different in shape (Fig. 5a, b). Herewith, within the above-mentioned temperature groups, the smallest scales were recorded in both species (Fig. 2a, b). After a separation of the allometric effect (nonallometric variation), these temperature groups did not differ in their scale shape. Moreover, increasing dome area in $M$. tonsurata connected with increasing temperature was revealed to be dependent on size. In analysis of non-allometric shape variation, no such trend was observed (compare Fig. 5b,d). The area of the dome seemed to be more or less constant, while the scale body decreased in size with increasing temperature. The dome serves as a place where silica bristles are attached to the scales. Therefore, it is likely to be not very variable in order to retain its function.

In both species, the highest extent of scale shape variation was revealed at the temperature of $25^{\circ} \mathrm{C}$ (the highest viable temperature). The highest extent of morphological disparity was observed in S. echinulata in suboptimal conditions such as a low temperature combined with a long-term low light intensity (Němcová et al., 2010). The most different shape patterns, observed in both species at $25^{\circ} \mathrm{C}$ together with increased scale shape variation (proved by geometric morphometrics analyses), may support the fact that the cells were stressed by this temperature. In general, the rise of morphological variation is considered to be a result of environmental stress (Ghalambor et al., 2007). However, to decide whether the response was adaptive or non-adaptive (stress induced), we need to determine stressing condition by parallel measurements of e.g. growth rates or the rate of photosynthesis. Remarkably, in $M$. tonsurata, the scale shape variation rose at both high and low temperatures. The $M$. tonsurata strain used in this study was isolated from an ice-covered pond.
However, synurophytes have been observed repeatedly to form dense populations in suboptimal temperature conditions (Martin-Wagenmann \& Gutowski, 1995; Gutowski, 1996; Saxby-Rouen et al., 1997; Lee \& Kim, 2007). Lower competition and predation pressure (Siver, 1995) as well as a higher content of dissolved carbon dioxide were listed to enhance population growth at low temperatures. Carbon dioxide is the key source of inorganic carbon for synurophyte photosynthesis as they are unable to utilise bicarbonate (Bhatti \& Colman, 2005, 2008).

In conclusion, we demonstrated that cultivation temperatures significantly affected silica scale shape and size and that all the individual temperature groups could be significantly discriminated according to their mean scale shape. However, taxonomically relevant characteristics of the scales did not change, e.g., all the scales were clearly recognisable as $S$. petersenii and $M$. tonsurata, respectively. Nevertheless, one must consider temperature to represent just one of the set of factors that influence organisms in nature. When experimentally obtained data are tested and verified in natural populations, they may provide new insights into palaeoecological research and bioindications.

Acknowledgments This study was supported by the Czech Ministry of Education, research grant No. 0021620828 and grant No. 206/08/P281 from the Czech Science Foundation.

\section{References}

Andersen, R. A., S. L. Morton \& J. P. Sexton, 1997. ProvasoliGuillard National Center for Culture of Marine Phytoplankton 1997. List of strains. Journal of Phycology 33(suppl): 1-75.

Atkinson, D., 1994. Temperature and organism size-a biological law for ectotherms? Advances in Ecological Research 25: 1-58.

Atkinson, D., B. J. Ciotti \& D. J. S. Montagnes, 2003. Protists decrease in size linearly with temperature: ca. $2.5 \%{ }^{\circ} \mathrm{C}^{-1}$. Proceedings of the Royal Society of London Series B-Biological Sciences 270: 2605-2611.

Bhatti, S. \& B. Colman, 2005. Inorganic carbon acquisition by the chrysophyte alga Mallomonas papillosa. Canadian Journal of Botany 83: 891-897.

Bhatti, S. \& B. Colman, 2008. Inorganic carbon acquisition in some synurophyte algae. Physiologia Plantarum 133: 33-40.

Bookstein, F. L., 1991. Morphometric Tools for Landmark Data: Geometry and Biology. Cambridge University Press, Cambridge.

Bookstein, F. L., 1997. Landmark methods for forms without landmarks: morphometrics of group differences in outline shape. Medical Image Analysis 1: 225-243. 
Černá, K. \& J. Neustupa, 2010. The pH-related morphological variations of two acidophilic species of Desmidiales (Viridiplantae) isolated from a lowland peat bog, Czech Republic. Aquatic Ecology 44: 409-419.

Debat, V., M. Bégin, H. Legout \& J. R. David, 2003. Allometric and nonalometric components of Drosophila wing shape respond differently to developmental temperature. Evolution 57: 2773-2784.

Ghalambor, C. K., J. K. McKay, S. P. Carroll \& D. N. Reznick, 2007. Adaptive versus non-adaptive phenotypic plasticity and the potential for contemporary adaptation in new environments. Functional Ecology 21: 394-407.

Grant, J., Y. I. Tekle, O. R. Andersen, D. J. Patterson \& L. A. Katz, 2009. Multigene evidence for the placement of a heterotrophic amoeboid lineage Leukarachnion sp. among photosynthetic stramenopiles. Protist 160: 38-376.

Gutowski, A., 1996. Temperature dependent variability of scales and bristles of Mallomonas tonsurata Teiling emend. Krieger (Synurophyceae). Nova Hedwigia Beiheft 114: $125-146$.

Hammer, O., D. A. T. Harper \& P. D. Ryan, 2001. PAST: Paleontological Statistics software package for education and data analysis. Palaeontologia Electronica 4. (http:// folk.uio.no/ohammer/past).

Hillebrand, H., C.-D. Dürselen, D. Kirschel, U. Pollinger \& T. Zohary, 1999. Biovolume calculation for pelagic and benthic microalgae. Journal of Phycology 35: 403-424.

Janatková, K. \& Y. Němcová, 2009. Silica-scaled chrysophytes of Southern Bohemian water bodies, including Mallomonas conspersa Dürrschmidt with occurrence so far reported from Japan and New Zealand. Fottea 9: 93-99.

Jolliffe, I. T., 1986. Principal Component Analysis. Springer, New York.

Kristiansen, J., 1979. Problems in classification and identification of Synuraceae (Chrysophyceae). Schweizerische Zeitschrift für Hydrologie-Swiss Journal of Hydrology 40: 310-319.

Kristiansen, J. \& H. R. Preisig, 2007. Chrysophyte and haptophyte algae. Part 2: Synurophyceae. In Büdel, B., G. Gärtner, L. Krienitz, H. R. Preisig \& M. Schagerl (eds), Süsswsserflora von Mitteleuropa 2/2. Springer Verlag, Berlin Heidelberg: 1-252.

Lavau, S. \& R. Wetherbee, 1994. Structure an development of the scale case of Mallomonas adamas (Synurophyceae). Protoplasma 181: 259-268.

Leadbeater, B. S. C. \& D. A. N. Barker, 1995. Biomineralization and scale production in the Chrysophyta. In Sandgren, C. D., J. P. Smol \& J. Kristiansen (eds), Chrysophyte Algae. Cambridge University Press, Cambridge: 303-329.

Lee, K. L. \& H. S. Kim, 2007. G.rowth characteristics of three synurophytes (Mallomonas species) at different temperatures and $\mathrm{pH}$. Nova Hedwigia 84: 227-240.

Marroig, G., 2007. When size makes a difference: allometry, life-history and morphological evolution of capuchins (Cebus) and squirrels (Saimiri) monkeys (Cebinae, Platyrrhini). BMC Evolutionary Biology 7: 20.

Martin-Wagenmann, B. \& A. Gutowski, 1995. Scale morphology and growth characteristics of clones of Synura petersenii (Synurophyceae) at different temperatures. In Sandgren, C. D., J. P. Smol \& J. Kristiansen (eds),
Chrysophyte Algae. Cambridge University Press, Cambridge: $345-360$.

Montagnes, D. J. S. \& D. J. Franklin, 2001. Effect of temperature on diatom volume, growth rate, and carbon and nitrogen content: reconsidering some paradigms. Limnology and Oceanography 46: 2008-2018.

Němcová, Y., 2010. Diversity and ecology of silica-scaled chrysophytes (Synurophyceae, Chrysophyceae) in the National Nature Monument Swamp and Břehyňský Pond, Czech Republic. Cryptogamie, Algologie 31: 229-243.

Němcová, Y., J. Neustupa, J. Kvíderová \& M. ŘezáčováŠkaloudová, 2010. Morphological plasticity of silica scales of Synura echinulata (Synurophyceae) in crossed gradients of light and temperature-a geometric morphometric approach. Nova Hedwigia Beiheft 136: 21-32.

Neustupa, J. \& L. Hodač, 2005. Changes in shape of the coenobial cells of an experimental strain of Pediastrum duplex var. duplex (Chlorophyta) reared at different $\mathrm{pHs}$. Preslia 77: 439-452.

Neustupa, J. \& Y. Němcová, 2007. A geometric morphometric study of the variation in scales of Mallomonas striata (Synurophyceae, Heterokontophyta). Phycologia 46: 123-130.

Neustupa, J. \& M. Řezáčová, 2007. The genus Mallomonas (Mallomonadales, Synurophyceae) in several Southeast Asian urban water bodies - the biogeographic implications. Nova Hedwigia 84: 249-259.

Neustupa, J., J. Šťastný \& L. Hodač, 2008. Temperature-related phenotypic plasticity in the green microalga Micrasterias rotata. Aquatic Microbial Ecology 51: 77-86.

Neustupa, J., M. Řezáčová-Škaloudová \& Y. Němcová, 2010. Shape variation of the silica scales of Mallomonas kalinae (Mallomonadales, Synurophyceae) in relation to their position on the cell body. Nova Hedwigia Beiheft 136: 33-42.

Padisák, J., L. S. Péterfi \& L. Momeu, 2000. Silica-scaled chrysophytes from Hungary. Verhandlungen des Internationalen Verein Limnologie 27: 131-134.

Řezáčová-Škaloudová, M., J. Neustupa \& Y. Němcová, 2010. Effect of temperature on the variability of silicate structures in Mallomonas kalinae and Synura curtispina (Synurophyceae). Nova Hedwigia Beiheft 136: 55-70.

Rohlf, F. J., 2006. Tps Series. Department of Ecology and Evolution, State University of New York at Stony Brook, New York.

Rojackers, R. M. \& H. Kessels, 1986. Ecological characteristics of scale-bearing Chrysophyceae from the Netherlands. Nordic Journal of Botany 6: 373-383.

Saxby-Rouen, K. J., B. S. C. Leadbeater \& C. S. Reynolds, 1997. The growth response of Synura petersenii (Synurophyceae) to photon flux density, temperature and $\mathrm{pH}$. Phycologia 36: 233-243.

Siver, P. A., 1991. The biology of Mallomonas - morphology, taxonomy and ecology. Kluwer Academic Publishers, London.

Siver, P. A., 1995. The distribution of chrysophytes along environmental gradients: their use as biological indicators. In Sandgren, C. D., J. P. Smol \& J. Kristiansen (eds), Chrysophyte Algae. Cambridge University Press, Cambridge: $345-360$. 
Siver, P. A. \& A. Skogstad, 1988. Morphological variation and ecology of Mallomonas crassisquama (Chrysophyceae). Nordic Journal of Botany 8: 99-107.

Smol, J. P., 1995. Application of chrysophytes to problems in paleoecology. In Sandgren, C. D., J. P. Smol \& J. Kristiansen (eds), Chrysophyte algae. Cambridge University Press, Cambridge: 345-360.

Wetherbee, R., M. Ludwig \& A. Koutoulis, 1995. Immunological and ultrastructural studies of scale development and deployment in Mallomonas and Apedinella. In Sandgren, C. D., J. P. Smol \& J. Kristiansen (eds), Chrysophyte Algae. Cambridge University Press, Cambridge: $345-360$.

Zelditch, M. L., D. L. Swiderski, H. D. Sheets \& W. L. Fink, 2004. Geometric Morphometrics for Biologist: A Primer. Elsevier Academic Press, New York: 1-443. 